\title{
Surgeons warn against tongue splitting due to high risks
}

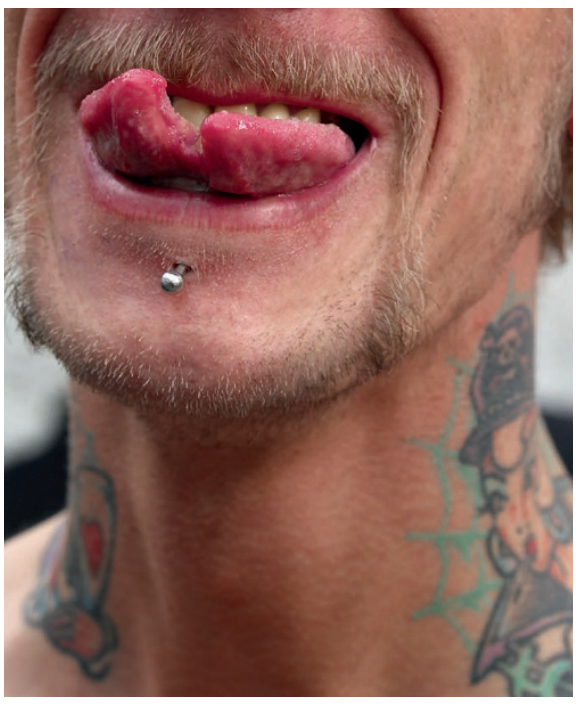

Dental and plastic surgeons have warned that people keen on undergoing tongue splitting - a procedure where the tongue is cut in half to create a distinctive 'forked' effect - are putting themselves at serious risk of haemorrhage, infection and nerve damage.

In a joint statement, the Faculty of Dental Surgery (FDS) at the Royal College of Surgeons and the British Association of Plastic Reconstructive and Aesthetic Surgeons (BAPRAS) warn that following a recent Court of Appeal ruling, body modification practitioners in England and Wales offering tongue splitting are now likely to be doing so illegally.

The professional bodies said they were concerned that the legal status of tongue splitting in the rest of the United Kingdom remained unclear.

Currently, around $10 \%$ of adults in England are estimated to have some form of body piercing and $1.5 \%$ of adults have a tongue piercing while $0.6 \%$ have a lip piercing.

FDS and BAPRAS warned that oral piercings such as tongue and lip piercings carried a risk of various adverse consequences such as:

- Inhalation and ingestion

- Tooth fracture

- Gum damage

- Infection

- Oral lesions

- Adverse reactions to local anaesthetic

- Swelling that can lead to breathing difficulties.
Worryingly, they said, more than half of tongue piercings and one in five lip piercings performed on young adults (aged 16-24) were believed to result in complications.

While body modification practitioners are known to offer tongue splitting as a service alongside regulated procedures such as tattooing and piercing, there has been uncertainty over the legal status of tongue splitting for some time - it is not covered under any existing legislation, so is in effect, unregulated.

However, in England and Wales, a Court of Appeal judgement recently found tongue splitting to be illegal, constituting grievous bodily harm, when performed by a body modification practitioner for cosmetic purposes, even in instances where consent has been obtained.

Selina Master, Junior Vice Dean of the Faculty of Dental Surgery at the RCS, said: 'As dental surgeons, weve seen some of the horrific consequences of these procedures. It's so important that people realise they are putting themselves at serious risk of significant blood loss, infection, nerve damage and problems being able to breath or swallow.

'In England and Wales, practitioners who offer tongue splitting are doing so illegally as the law currently stands. There is an urgent need for the law in other parts of the UK to be clarified. We would strongly advise people not to have oral piercings or tongue splits, but if they do, it is crucial they see their dentist on a regular basis so that the impact on their oral health can be closely monitored.'

Commenting on tongue splitting, the President of BAPRAS, Mr David Ward, said: 'No reputable surgeon would undertake this procedure as it carries high risks, both at the time of the procedure and long term, there are no medical reasons for doing it, and in England and Wales, and maybe elsewhere in the United Kingdom, it is probably illegal.'

At the start of this year Wales became the first country in the United Kingdom to ban tongue piercing for anyone under the age of 18 .

1. FDS and BAPRAS. Joint Statement on Oral Piercing and Tongue Splitting (3 August 2018). http://www.bapras. org.uk/docs/default-source/News-cuttings/fds-baprasjoint-statement-on-oral-piercing-and-tongue-splittingfinal.pdf?sfvrsn=2 (accessed 13 August 2018). 